\title{
Müsabaka Dönemi Antrenmanlarının Voleybolcuların Fiziksel Uygunluk
}

\section{Profillerine Etkisi}

Ramazan ERDOĞAN ${ }^{1}$ (D)
ISSN: 2536-5339

\footnotetext{
${ }^{1}$ Gençlik ve Spor Bakanlığı, Elazığ Gençlik ve Spor İl Müdürlüğü, $E L A Z I \breve{G}$

${ }^{2}$ Frrat Üniversitesi, Spor Bilimleri Fakültesi, ELAZIĞ
}

DOI: 10.31680/gaunjss.732657

Orijinal Makale / Original Article

Geliş Tarihi / Received: 05.05.2020

\author{
Mikail TEL ${ }^{2}$ (D)
}

Abdulsamet EREN ${ }^{1 *}$ (D)

Öz

Uzun süre uygulanan antrenman programları sporcuların gelişimi ve sportif performansı geliştirmek ve sürdürebilmek için önem arz etmektedir. Bu bilgiler ışığında araştırmada müsabaka döneminde uygulanan voleybol ve dayanıklılık antrenmanlarının voleybolcuların fiziksel uygunluk profillerini etkisini belirmek amacıyla yapıldı. Araştırma grubunu voleybol takımlarında oynayan 20 sporcu oluşturmaktadır. Araştırmaya katılan sporculara üç ay süreyle bir günü kondisyona yönelik antrenman olmak üzere haftada beş gün ve günde seksen dakika olmak üzere kondisyonel ve voleybola yönelik antrenman uygulanmıştır. Araştırmaya katılan sporculardan antrenmanlara başlanmadan ve bitiminde olmak üzere boy, vücut ağırlığı, dikey sıçrama, esneklik, el kavrama kuvveti, reaksiyon hızı ve bacak kuvveti ölçümleri alındı. Verilerin analizinde Paired Samples T testi kullanıldı ve anlamlılık düzeyi $p>0,05$ kabul edildi. Araştırma sonuçlarında voleybol sporcularının, bacak kuvveti, el kavrama kuvvetleri, dikey sıçrama, esneklik, yirmi ve otuz metre, çeviklik, işitsel ve görsel reaksiyon değerlerinde istatiksel olarak farklııı olduğu $(p<0,05)$, on metre değerinde istatistiksel olarak farklılığının olmadığı belirlendi $(p>0,05)$. Sonuç olarak, düzenli olarak uygulanan antrenmanlarının sporcuların fiziksel uygunluk profillerini önemli derecede etkilediği belirlenmiştir. Bu bağlamda uygulanan antrenmanların sporcuların atletik performansını ve sağlığını olumlu yönde etkileyeceği düşünülmektedir.

Anahtar Kelimeler: Voleybol, Antrenman, Fiziksel Uygunluk

\section{Effect of Competition Period Training on Volleyball Players' Physical Fitness Profiles}

\begin{abstract}
Long-term training programs are important for improving and sustaining the development and sporting performance of the athletes. In the light of this information, the research was conducted to determine the effect of volleyball and endurance training during the competition period on the physical fitness profiles of volleyball players. The research group consists of 20 athletes who play on volleyball teams. The athletes who participated in the study were given one day of fitness training for three months, five days a week, and eighty minutes a day of physical and volleyball training. Height, body weight, vertical jump, flexibility, hand grip strength, reaction rate and leg strength were measured from the athletes who participated in the study before and after the training. Paired Samples $t$ Test was used in the analysis of the data and the significance level was considered to be $p>0.05$. The results of the study showed that there were statistically differences in leg strength, hand grip strength, vertical jump, flexibility, twenty and thirty meters, agility, auditory and visual reaction values of volleyball athletes $(p<0.05)$ and there were statistically no differences in ten meters value $(p>0.05)$. As a consequence, it was determined that regular practice significantly affected the physical fitness profiles of the athletes. In this context, it is thought that the training will positively affect the athletic performance and health of the athletes.
\end{abstract}

Keywords: Volleyball, Training, Physical Fitness

\footnotetext{
* Sorumlu Yazar: Ramazan ERDOĞAN
}

E-mail: ramaznerdogan@hotmail.com 


\section{Giriş}

Farklı spor branşlarında mücadele eden sporcuların karakteristik özelliklerini tanımlamak üzere çok fazla araştırma yapılmıştır ve yapılmaya devam etmektedir. Yapılan araştırmalarda genel olarak elit seviyedeki sporcuların başarılı olması veya belirledikleri hedeflere ulaşması için gerekli olan fiziksel, fizyolojik ve psikolojik özelliklerini belirlemeyi amaçlamışlardır. Doğal olarakta bu durum bireysel sporlara nazaran voleybol gibi takım sporlarında çok sayıda sporcunun yer alması sebebiyle biraz daha karmaşık hale getirir (Dilber ve ark., 2016). Tüm bu etkenler göz önüne alındığında sporcuların atletik performanslarını belirlenen hedeflere ulaşması için uygulanan antrenmanlarla birlikte teknoloji ve bilim insanlarının da yer aldığı kombin çalışmalar halen ilgi odağı olmaya devam etmektedir.

Tüm spor branşlarında sporcuların performansını arttırıması için antrenmanlarla beraber bilimsel yöntemlerin kullanılması önemlidir. Günümüzde tüm spor branşlarında hız, beceri, antropometrik ve fizyolojik kapasitelerinin üst seviyede olması gerekmektedir (Albay ve ark., 2008). Sporcuların belirtilen özeliklerin yanı sıra temel motorik özelliklerinin ( dayanıklılık, kuvvet, sürat, çeviklik esneklik, beceri vb.) gelişimi spor branşına özgü uygulanan antrenmanlar ile gerçekleşebilir (Akyüz, 2017; Kızılet ve ark., 2010). Uygulanacak antrenmanlarla sporcuların performans düzeyinin en üst seviyeye çıkarmak ve bu seviyeyi korumak hedeflenmektedir.

Belirlenen hedeflere ulaşabilmek için voleybolcuların fiziksel profilinin belirlenerek antrenörlerin bu kriterleri göz önünde bulundurarak antrenmanları dizayn etmesi gerekmektedir. Bu sebeple tüm bu etkenler dikkate alınarak alt yapıdan başlanarak sporcuların fiziksel yapısının yanı sıra teknik ve taktiksel becerilerinin eğitimlerine önem verilmesi gerekmektedir. Bu bağlamda antrenörler antrenman programlarını çalışmalar neticesinde sporcuların yeni kazanımlar elde etmesinin yanında performans ve temel motorik özelliklerini geliştirmeyi amaçlamaktadırlar (Ergün ve Arıkan, 2019).

$\mathrm{Bu}$ araştırmada müsabaka döneminde uygulanan voleybol ve dayanıklılık antrenmanlarının voleybolcuların fiziksel uygunluk profillerini etkisini belirmek amacıyla yapıldı. 


\section{Yöntem}

\section{Araştırma Grubu}

Araştırma grubunu voleybol branşında lisanslı ve düzenli olarak antrenmanlara katılan 20 erkek sporcu gönüllü olarak katıldı.

\section{Antrenman Programı}

Araştırmaya katılan sporculara üç ay boyunca bir günü kondisyonel özelliklere yönelik haftada beş gün ve günde seksen dakika olmak üzere bir antrenman programı uygulandı. Antrenman programı kapsamında bir antrenman biriminde, 10-15 dakikalık ısınma, 45-50 dakikalık temel voleybol eğitimi veya kondisyonel özellikleri geliştirmeye yönelik antrenman uygulanmış olup, antrenman bitiminde 5-10 dakikalık soğuma egzersizleri uygulandı. Uygulanan antrenman programı voleybolcuların maksimal kalp atım hızının \%50-65 göre ayarlandı. Egzersiz programının şiddeti Karvonen metoduna göre dizayn edilmiştir.

\section{Araştırmada Uygulanan Ölçüm ve Testler}

Vücut Ağırlığı ve Boy Uzunluğu: Sporcuların vücut ağırlıklarını belirlenmek için dijital tartı kullanıldı ve belirlenen değerler kg cinsinden kaydedildi. Sporcuların boy uzunluklarını belirlemek için düz bir duvar yüzeyine sabitlenen mezura yardımıyla belirlendi ve ölçülen değerler $\mathrm{cm}$ cinsinden kaydedildi.

Sırt-Bacak Kuvveti: Sporcuların bacak kuvvetleri, Takkei marka (Takei-Back\&Lift, Japonya) sırt-bacak (back and lift) dinamometresiyle belirlendi. Sporcuların dizleri hafifçe bükülü bir biçimde dinamometre sehpasının üzerine ayaklarını yerleştirdikten sonra kollar gergin, sırt düz ve gövde hafif şekilde öne doğru, sağ-sol el ile kavrayarak dinamometre barının dikey olarak maksimum oranda bacaklarını kullanarak yukarı çekti. Ölçümler iki kez tekrar edildi ve en iyi sonuç kaydedildi (Karakulak ve ark., 2019).

El Kavrama Kuvveti: Sporcuların el kavrama kuvvetleri ölçümlerini, hassasiyeti $0.100 \mathrm{~kg}$ olan Takkei marka cinsi el dinamo metresi ile (Hand grip) belirlendi. El kavrama kuvveti ölçümleri sporcular ayakta, kollarını bükmeyecek şekilde ve elleri vücuda temas etmeyecek biçimde yapıldı. Ölçümler her iki el içinde iki kez tekrarlandı ve en iyi sonuç kg cinsinden kaydedildi (Işın ve ark., 2018).

Dikey Sıçrama Testi: Sporcuların dikey sıçrama değerlerini belirlemek için Smartspeed marka mat kullanılarak belirlendi. Sporcuların yerde bulunan sıçrama 
matının üzerinde ve ellerini beline koyarak kendisini hazır hissettiğinde yukarı doğru sıçranması istendi. Ölçümler iki defa tekrar edildi en iyi derece $\mathrm{cm}$ cinsinden kaydedildi (Ayan ve ark., 2019).

Sürat Testi $(10,20,30$ metre): Sürat testleri başlanmadan önce ısınmaları için sporculara yeterli süre verildi ve sporcuların tek tek 10, 20,30 metrelik parkurun başlangıç çizgisine yerleştirildi. Sporculara çıkış işareti verildikten sonra başlangıç çizgisinden geçerek maksimal hızda bitiş çizgisini geçmeleri istendi. Katılımcıların başlangıç ve bitiş çizgisine kadar geçen süre fotoselle belirlendi. Katılımcıların sürat değerleri ölçümleri iki kez tekrarlandı ve en iyi derece sn cinsinden kaydedildi.

Esneklik Testi: Sporcuların esneklik değerleri otur uzan testi ile belirlendi. Sporcuların esneklik değerlerini belirlemek için; katılımcılardan yere oturur vaziyette ve çıplak ayak tabanını düz bir şekilde test sehpasına gelecek şekilde yerleştirilmesi, gövdesi ileriye doğru ve dizlerini bükmeyecek biçimde uzanabilecekleri son noktaya kadar uzanmaları ve bu biçimde bir iki saniye beklemeleri istendi. Esneklik değerleri ölçümleri iki defa tekrarlandı ve en iyi sonuç cm cinsinden kaydedildi (Boynaz ve ark., 2017).

Pro-Agility Çeviklik Testi: Sporcuların çeviklik değerlerini, 20 yard koşu testi olarak bilinen pro-agility çeviklik testi ile belirlendi. Test alanı, başlangıç çizgisinin 5 yard $(4,57 \mathrm{~m})$ sağ ve sol kısımlarına huniler yerleştirilerek belirlenir. Başlangıç çizgisine fotosel kapısı yerleştirilerek ve tekrarlı geçiş süreleriyle sporcuların çeviklik değerleri belirlenir. Çeviklik testine başlanmadan önce sporcu başlangıç çizgisindeki yerini alır ve başlama komutu ile teste başlanır önce sağdaki huniye, sonra da soldaki huniye dokunarak başlangıç çizgisinden geçerek test sonlandırılır. Çeviklik testi iki defa tekrarlandı ve en iyi derece $\mathrm{cm}$ saniye cinsinden kaydedildi (Başturk ve ark., 2019).

Reaksiyon Zamanı Testi: Sporcuların reaksiyon değerlerini New-test reaksiyon cihazı kullanılarak belirlendi. Sporculara ölçümler öncesinde 5 dakika süre ile reaksiyon zamanı ölçümleri öğretilerek öğrenme faktörlerinin etkileri standartlaştııılı. Sporcuların reaksiyon ölçümleri sessiz ve yeterli düzeyde ışığın bulunduğu bir ortamda gerçekleştirildi. Reaksiyon ölçümleri on kez tekrarlandı, çok düşük iki ve çok yüksek iki değerler değerlendirilmeye tabi tutulmadı ve birbirine yakın altı değerin ortalaması alınarak reaksiyon süresi belirlendi ve saniye cinsinden kaydedildi (Karagöz ve ark., 2017). 


\section{Verilerin Analizi}

Verilerin SPSS istatistik paket programı kullanılarak analiz edildi.. Verilerin normallik analizi için Shapıro Wılk-W normallik testi uygulandı. Verilerin normal dağılım gösterdiği belirlendikten sonra araştırma grubunun ön-son test değerlerinin karşılaştırıması için Paired Samples T testi uygulandı. Anlamlılık düzeyi $p<0,05$ olarak değerlendirildi.

\section{Bulgular}

Tablo 1. Sporcularının Demografik Durumuna İlişkin Özellikleri

\begin{tabular}{|c|c|c|c|}
\hline Ölçümler & $\mathrm{N}$ & $\bar{X}$ & Ss \\
\hline Yaş(yıl) & 20 & 13,55 & 1,05 \\
\hline Boy $(\mathrm{cm})$ & 20 & 163,25 & 11,81 \\
\hline Vücut ağırı̆ğı (kg) & 20 & 47 & 3 \\
\hline Spor Yaşı (yıl) & 20 & 2,95 & 1,09 \\
\hline
\end{tabular}
incelendiğinde; yaş, boy, vücut ağırlıkları ve spor yaşları ortalamaları sırasıyla

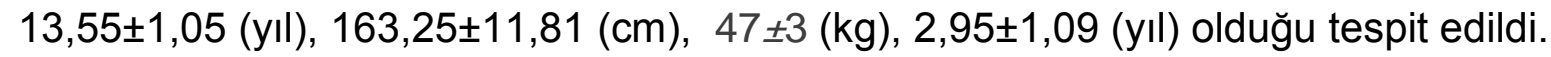

Tablo 2. Sporcularının Fiziksel Profil Ön-Son Test Sonuçları

\begin{tabular}{|c|c|c|c|c|c|c|}
\hline \multirow{2}{*}{ Ölçümler } & \multicolumn{2}{|c|}{ Ön Test } & \multicolumn{2}{|c|}{ Son Test } & \multirow[b]{2}{*}{$\mathbf{t}$} & \multirow[b]{2}{*}{$\mathbf{p}$} \\
\hline & $\bar{X}$ & Ss & $\bar{X}$ & Ss & & \\
\hline Bacak Kuvveti (kg) & 66,97 & $\begin{array}{c}18,7 \\
2\end{array}$ & 78,90 & 17,64 & $-3,499$ & $0,000^{*}$ \\
\hline $\begin{array}{l}\text { Sağ El Kavrama Kuvveti } \\
(\mathrm{kg})\end{array}$ & 27,42 & 8,06 & 30,25 & 8,23 & $-3,193$ & $0,000^{*}$ \\
\hline $\begin{array}{l}\text { Sol El Kavrama } \\
\text { Kuvveti(kg) }\end{array}$ & 26,93 & 9,08 & 29,58 & 9,06 & $-4,739$ & $0,000^{*}$ \\
\hline Dikey sıçrama(cm) & 38,39 & 6,81 & 41,09 & 5,82 & $-2,576$ & $0,000^{*}$ \\
\hline $10 \mathrm{mt}$ Sürat(sn) & 1,93 & 0,22 & 1,86 & 0,15 & 1,403 & $0,013^{*}$ \\
\hline 20 mt Sürat(sn) & 3,30 & 0,36 & 3,23 & 0,35 & 3,201 & $0,000^{*}$ \\
\hline 30 mt Sürat(sn) & 4,80 & 0,37 & 4,62 & 0,37 & 3,397 & $0,000^{*}$ \\
\hline Çeviklik (sn) & 5,70 & 0,28 & 5,59 & 0,33 & 2,591 & $0,001^{*}$ \\
\hline İşitsel Reaksiyon (sn) & 0,23 & 0,05 & 0,21 & 0,03 & $-1,107$ & $0,001^{*}$ \\
\hline Görsel Reaksiyon (sn) & 0,18 & 0,03 & 0,20 & 0,02 & 2,024 & 0,246 \\
\hline Esneklik & 32,77 & 4,65 & 38,72 & 4,89 & $-3,294$ & $0,000^{*}$ \\
\hline
\end{tabular}

${ }^{\star} p<0.05$

Tablo 2' de araştırma grubunun fiziksel profilleri değerlendirildiğinde; bacak kuvveti, el kavrama kuvvetleri, çeviklik, , esneklik, işitsel reaksiyon, on metre, yirmi metre ve otuz metre değerlerinde istatiksel olarak farklılık olduğu $(p<0,05)$, görsel 
Erdoğan R, Tel M, Eren A. (2020). Müsabaka Dönemi Antrenmanlarının Voleybolcuların Fiziksel Uygunluk Profillerine Etkisi. Gaziantep Üniversitesi Spor Bilimleri Dergisi, 5(2), 194-206.

reaksiyon değerlerinde ise istatiksel olarak anlamlı bir farklılık olmadığı tespit edildi $(p>0,05)$.

\section{Tartışma ve Sonuç}

Atletik performansın geliştirilmesinde temel motorik özelliklerin yanı sıra fiziksel profillerinde gelişim kaydetmesi önemli bir göstergedir. Bu bilgiler ışığında uygulanan antrenman programları sporcuların fiziksel ve fizyolojik özelliklerini etkilediği bilinmektedir. Bu araştırmada müsabaka döneminde uygulanan antrenman programlarının voleybolcuların temel motorik özelliklerinin yanı sıra fiziksel uyguluk düzeylerine etkisi belirlendi.

Araştırma bulgularımızda voleybolcuların sağ el kavrama kuvvetleri antrenman öncesi $27,42 \pm 8,06 \mathrm{~kg}$, antrenman sonrası $30,25 \pm 8,23 \mathrm{~kg}$, sol el kavrama kuvvetleri antrenman öncesi $26,93 \pm 9,08 \mathrm{~kg}$, antrenman sonrası $29,58 \pm 9,06 \mathrm{~kg}$ belirlendi. Voleybolcuların uygulanan antrenmanlar neticesinde sağ-sol el kavrama kuvvetleri karşılaştırıldığında antrenman öncesi-sonrası değerleri karşılaştırıldığında istatiksel farklılık olduğu belirlendi. Aktaş ve ark., (2011) sekiz haftalık kuvvet antrenmanları uyguladığı araştırmada sporcuların el kavrama kuvvetlerini pozitif yönde etkilediğini tespit etmişlerdir. Kürkçü (2009) yaptığı çalışmada on iki haftalık antrenman programının sporcuların sürat, esneklik, anaerobik ve el kavrama kuvvetlerini arttırdığını tespit etmiştir. Yapılan farklı bir çalışmada García-Pinillos ve ark., (2015) akut bir egzersiz sonucu sporcularda egzersiz sonrası oluşan yorgunluğa rağmen dikey sıçrama ve el kavrama kuvvetlerini koruduğunu belirtmişlerdir. Başka bir çalışmada Yurkevicius ve ark., (2020) hipobarik bir odada otuz saatlik simule edilmiş yüksek irtifaya maruz kalan katılımcıların el kavrama kuvvetlerini etkilemediğini tespit etmişlerdir.

Araştırmaya katılan voleybolcuların bacak kuvveti değerleri antrenman öncesi $66,97 \pm 18,72 \mathrm{~kg}$, antrenman sonrası $78,90 \pm 17,64 \mathrm{~kg}$, olduğu belirlendi. Voleybolcuların uygulanan antrenmanlar sonucunda antrenman öncesi-sonrası bacak kuvveti değerleri kıyaslandığında istatiksel olarak anlamlı bir farklılık olduğu görüldü. Küçükbaycan ve ark., (2013) voleybolcularda uyguladığı hazırlık dönemi antrenmanlarının sporcuların bacak kuvveti değerlerini olumlu yönde artış sağladığını belirlemiştirler. Ölçücü ve ark., (2011) on iki haftalık antrenman programı uyguladıkları çalışmada sporcuların bacak kuvveti değerlerini geliştirdiğini tespit etmişlerdir. Pérez-Turpin ve ark., (2014) altı haftalık kuvvet antrenmanı uyguladığı 
çalışmada voleybolcuların bacak kuvveti değerlerini önemli ölçüde etkilediğini tespit etmişlerdir. İmamoğlu ve ark., (2017) yaptıkları araştırmada sekiz haftalık hazırlık dönemi antrenmanlarının sporcularının bacak kuvveti değerlerini önemli ölçüde etkilediğini belirlemişlerdir. Benzer bir çalışmada Popelka ve Pavlović (2015) müsabaka dönemi süresince uyguladıkları antrenmanların bacak kuvveti değerlerini pozitif yönde etkilediğini tespit etmişlerdir.

Araştırma sonuçlarına göre voleybolcuların dikey sıçrama değerleri antrenman

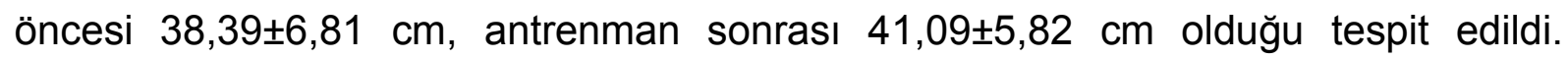
Voleybolcuların yapılan çalışma neticesinde antrenman öncesi-sonrası dikey sıçrama değerleri karşılaştırıldığında istatiksel açıdan farklılık olduğu belirlendi. Martel ve ark., (2005) altı haftalık antrenman programının voleybolcuların dikey sıçrama değerlerini pozitif yönde etkilediğini belirlemişlerdir. Demirci ve ark., (2017) yaptıkları çalışmada altı hafta süresince deney 1 grubuna sadece tenis antrenmanı deney 2 grubuna tenis antrenmanı ile birlikte dört dakikalık sekiz egzersizden oluşan bir tabata protokolü uygulanarak sporcuların dikey sıçrama değerlerine etkisi incelenmiştir. Araştırma neticesinde uygulanan antrenmanlar sonucunda deney 2 grubunda dikey sıçrama değerlerinde olumlu yönde gelişmeler kaydedildiğini belirtmişlerdir. Pancar ve ark., (2018) yaptıkları çalışmada sekiz haftalık pliometrik antrenman programının hentbolcuların dikey sıçrama değerlerini olumlu yönde geliştirdiğini belirlemişlerdir. Fattahi ve ark., (2015) yaptıkları çalışmada sekiz haftalık antrenman programının voleybolcuların dikey sıçrama çeviklik ve bacak kuvvetlerinde olumlu yönde gelişmeler sağlandığını tespit etmişlerdir. Başka bir çalışmada Krističević, ve ark., (2016) beş haftalık pliometrik antrenmanların voleybolcuların dikey sıçrama değerlerini anlamlı bir şekilde gelişme gösterdiğini tespit etmişlerdir. Göktepe ve ark., (2019) sekiz haftalık haftada iki gün uyguladıkları antrenman programının kadın futbolcularda dikey sıçrama değerlerini etkilediğini tespit etmişledir.

Araştırmaya katılan voleybolcuların sürat değerlerine incelendiğinde sırasıyla, 10 metre antrenman öncesi $1,93 \pm 0,22 \mathrm{sn}$, antrenman sonrası $1,86 \pm 0,15 \mathrm{sn}, 20$ metre antrenman öncesi $3,30 \pm 0,36 \mathrm{sn}$, antrenman sonrası 3,23 $\pm 0,35 \mathrm{sn}, 30$ metre antrenman öncesi $4,80 \pm 0,37 \mathrm{sn}$, antrenman sonrası $4,62 \pm 0,37$ sn olduğu belirlendi.Voleybolcuların uygulanan antrenmanlar neticesinde antrenman öncesisonrası sürat değerleri kıyaslandığında istatiksel olarak anlamlı farklılığın olduğu tespit edildi. Voelzke ve ark., (2012) uyguladıkları beş haftalık kombine antrenmanların voleybolcuların çeviklik ve sürat değerlerini olumlu yönde geliştirdiğini 
belirtmişlerdir. Kaynak ve ark., (2017) voleybol antrenmanlarına ek olarak sürat antrenmanlarını uyguladıkları araştırmada voleybolcuların sürat değerleri pozitif yönde etkilediğini tespit etmişlerdir. Başka bir çalışmada Baron ve ark., (2020) uyguladıkları on iki haftalık bir antrenman programının sporcuları sürat değerlerinde olumlu yönde geliştirdiğini belirlemişlerdir. İnce (2019) yaptığı araştırmada altı haftalık halter antrenmanlarının voleybolcuların sürat değerlerini geliştirdiğini tespit etmiştir. Gjinovci ve ark., (2017) on iki haftalık bir antrenman uyguladığı çalışmada voleybolcuların sürat değerlerini olumlu yönde geliştirdiğini tespit etmişlerdir.

Araştırmaya katılan voleybolcuların çeviklik değerlerinin antrenman öncesi $5,70 \pm 0,28$ sn, antrenman sonrası 5,59 $\pm 0,33$ sn olduğu belirlendi. Voleybolcuların uygulanan antrenman programı neticesinde antrenman öncesi-sonrası çeviklik değerleri karşılaştırılı̆̆ında istatiksel olarak anlamlı farklılık olduğu belirlendi. Trajković, ve ark., (2020) sekiz haftalık antrenman programı uyguladığı araştırmada voleybolcuların çeviklik değerlerini olumlu yönde geliştirdiğini tespit etmişlerdir. Başka bir çalışmada Hopper, ve ark., (2017) altı haftalık bir egzersiz programının sporcuların çeviklik değerlerini önemli ölçüde etkilediğini belirtmişlerdir. Yapılan farklı bir çalışmada Çağlayan ve ark., (2018) on haftalık antrenman programı uyguladığı araştırmada voleybolcuların çeviklik değerlerini etkilemediğini belirlemişlerdir.

Araştırma bulgularında voleybolcuların esneklik değerlerinin antrenman öncesi $32,77 \pm 4,65 \mathrm{~cm}$, antrenman sonrası $38,72 \pm 4,89 \mathrm{~cm}$ olduğu belirlendi. Voleybolcuların uygulanan antrenmanlar neticesinde antrenman öncesi-sonrası esneklik değerleri kıyaslandığında istatistiksel olarak farklılık olduğu tespit edildi. Turki-Belkhiria ve ark., (2014) yaptıkları araştırmada sekiz haftalık antrenman programının esneklik seviyelerini olumlu yönde etkilediğini tespit etmişlerdir. Sarikaya ve ark., (2016) sekiz haftalık bir antrenman programı uyguladığı araştırmada sporcuların esneklik düzeylerinin olumlu yönde geliştiğini tespit etmişlerdir. Başka bir çalışmada Ryan ve ark., (2014) farklı germe egzersizleri içeren akut bir egzersiz programının katılımcıların esneklik değerlerini geliştirdiğini tespit etmişlerdir. Yapılan farklı bir çalışmada Elif ve ark., (2010) dört aylık voleybol antrenmanlarının sporcuların esneklik değerlerinin düştüğünü belirlemişlerdir. Akyüz ve ark., (2017) statik ve dinamik germe egzersizlerini içeren akut bir egzersiz programı uyguladığı çalışmada sporcuların esneklik düzeylerini geliştirdiğini tespit etmişlerdir.

Araştırmaya katılan voleybolcuların işitsel reaksiyon değerleri antrenman öncesi $0,23 \pm 0,05 \mathrm{sn}$, antrenman sonrası 0,21 $\pm 0,03 \mathrm{sn}$, görsel reaksiyon değerleri 
antrenman öncesi $0,18 \pm 0,03 \mathrm{sn}$, antrenman sonrası 0,20 $0,02 \mathrm{sn}$, olduğu belirlendi. Voleybolcuların uygulanan antrenman programı neticesinde antrenman öncesisonrası işitsel reaksiyon değerlerinde istatistiksel olarak farklılık olduğu, görsel reaksiyon değerlerinde istatistiksel olarak bir farklılık olmadığı tespit edildi. Çankaya ve ark., (2014) iki aylık denge geliştirici antrenman uygulamalarının katılımcıların reaksiyon sürelerini olumlu yönde etkilediğini tespit etmişlerdir. Çakıroğlu ve Sökmen (2012) on iki haftalık bir antrenman programı uyguladığı sporcularda reaksiyon sürelerinde olumlu yönde gelişme kaydedildiğini belirlemiştirler. Yapılan farklı çalışmada Mroczek ve ark., (2011) bir voleybol maçı süresince sporcuların reaksiyon sürelerinde değişimler olduğunu ancak bu değişimleri istatistiksel olarak anlamlı olmadığını belirlemiştir.

Araştırma sonucunda; müsabaka döneminde uygulanan voleybol antrenmanlarının sporcuların temel motorik özelliklerini olumlu yönde geliştirdiğini belirlenmiştir. Bu sonuçlar neticesinde müsabaka döneminde uygulanan antrenmanların sporcuların performansının gelişimi ve korunması açısından önemli olacağını düşünmekteyiz.

\section{Kaynaklar}

Aktaş F, Akkuş H, Harbili E, Harbili S. (2011). Kuvvet Antrenmanının 12-14 Yaş Grubu Erkek Tenisçilerin Bazı Motorik Özelliklerine Etkisi. Journal of Physical Education \& Sports Science/Beden Egitimi ve Spor Bilimleri Dergisi, 5(1).

Akyüz M, Özmaden M, Doğru Y, Karademir E, Aydın Y, Hayta Ü. (2017). Effect Of Static And Dynamic Stretching Exercises On Some Physical Parameters İn Young Basketball Players. Journal of Human Sciences, 14(2), 1492-1500.

Akyüz Ö. (2017). Müsabaka Dönemindeki Futbolcularda Sekiz Haftalık Antrenmanın Bazı Fiziksel Uygunluk Parametreleri Üzerine Etkisi. Gaziantep Üniversitesi Spor Bilimleri Dergisi, 2 (1) , 85-95.

Albay MD, Tutkun E, Ağaoğlu YS, Canikli A, Albay F. (2008). Hentbol, Voleybol Ve Futbol Üniversite Takımlarının Bazı Motorik Ve Antropometrik Özelliklerinin İncelenmesi. Spormetre Beden Eğitimi ve Spor Bilimleri Dergisi, 6(1), 13-20.

Ayan S, Boyalı E, Ergin M, Ulaş M. (2019). Özel Gereksinimli Öğrencilerin Seçili Fiziksel ve Temel Motor Parametrelerinin Yaş Ve Cinsiyet Değişkenleri Açısından İncelenmesi. Journal of International Social Research, 12(62). 
Baron J, Bieniec A, Swinarew AS, Gabryś T, Stanula A. (2020). Effect of 12-Week Functional Training Intervention on the Speed of Young Footballers. International Journal of Environmental Research and Public Health, 17(1), 160.

Başturk D, Çatalkaya Z, Seyhan ME, Açıkalın Y, Hondoroğlu K, Karataş H. (2019). Cimnastikte Sürat Çeviklik ve Denge İlişkisi. Türk Spor Bilimleri Dergisi, 2(2), 133-140.

Baynaz K, Acar K, Çinibulak E, Atasoy T, Mor A, Pehlivan B, Arslanoğlu E. (2017). Yüksek Yoğunluklu İnterval Antrenmanın Esneklik ve Anaerobik Kapasite Üzerine Etkisi. Journal of Human Sciences, 14(4), 4088-4096.

Çağlayan A, Kurt A, Çerçi B. (2018). Eksantrik ve Konsantrik Kas Çalışmaları ile Yapılan Kuvvet Çalışmalarının 15-18 Yaş Arası Voleybolcuların Sıçrama Performansı Üzerine Etkisi. Spor Eğitim Dergisi, 2(3), 1-10.

Çakıroğlu T, Sökmen T. (2012). 12 Haftalık Judo Teknik Antrenman ve Oyunlarının 8-10 Yaş Grubu Erkek Çocuklarda Reaksiyon Zamanı Üzerine Etkisi. Selçuk Üniversitesi Beden Eğitimi ve Spor Bilim Dergisi, 14 (1), 71-74.

Çankaya S, Gökmen B, Musa ÇON, Taşmektepligil M. (2014). Denge Geliştirici Özel Antrenman Uygulamalarının 11 Yaş Genç Erkeklerin Reaksiyon Zamanları ve Vücut Kitle İndeksi Üzerine Etkisi. Spor ve Performans Araştırmaları Dergisi, 5(2), 59-67.

Demirci D, Odabaş B, Özgür T, Bayır E. (2017). The Effects Of Tabata Protocol On Vertıcal Jump Among 14-16 Year-Old Male Tennıs Players. Journal of Physical Education \& Sports Science/Beden Egitimi ve Spor Bilimleri Dergisi, 11(3).

Dilber AO, Lağap B, Akyüz Ö, Çoban C, Akyüz M, Taş M, Özkan A. (2016). Erkek futbolcularda 8 Haftalık Kor Antrenmanının Performansla İlgili Fiziksel Uygunluk Değişkenleri Üzerine Etkisi. CBÜ Beden Eğitimi ve Spor Bilimleri Dergisi, 11(2), 77-82.

Elif O, Ahmet PH, Altunsoy M, Elvan O, Ozge PA. (2010). The Effects Of 4 Month Volleyball Training On Flexibility, Jump, Speed And Agility İn Preadolescent Girls. Ovidius university annals, series physical education and sport, 2, 558560. 
Ergün G, Arıkan Ş. (2019). Futbolcularda Hazırlık Dönemi Antrenmanlarının Bazı Motorik Parametreler Üzerine Etkisi. Kilis 7 Aralık Üniversitesi Beden Eğitimi ve Spor Bilimleri Dergisi, 3 (2) , 8-15.

Fattahi A, Kazemini H, Rezaei M, Rahimpour M, Bahmani M, Nia SS, Einanloo M. (2015). Effect Of Different Plyometric Training On Biomechanical Parameters Of Junior Male Volleyball Players. Journal of Scientific Research and Reports, 473-479.

García-Pinillos F, Soto-Hermoso VM, Latorre-Román PA. (2015). Acute Effects Of Extended İnterval Training On Countermovement Jump And Handgrip Strength Performance İ Endurance Athletes: Postactivation Potentiation. The Journal of Strength \& Conditioning Research, 29(1), 11-21.

Gjinovci B, Idrizovic K, Uljevic O, Sekulic D. (2017). Plyometric Training İmproves Sprinting, Jumping And Throwing Capacities Of High Level Female Volleyball Players Better Than Skill-Based Conditioning. Journal of sports science \& medicine, 16(4), 527.

Göktepe M, Göktepe MM, Güder F, Günay, M. (2019). The Effects Of Core Training Given To Female Soccer Players On Different Vertical Jumping Methods. Journal of Human Sciences, 16(3), 791-798.

Hopper A, Haff EE, Barley OR, Joyce C, Lloyd RS, Haff GG. (2017). Neuromuscular training improves movement competency and physical performance measures in 11-13-year-old female netball athletes. The Journal of Strength \& Conditioning Research, 31(5), 1165-1176.

Işın A, Özus ÇBÖ, Melekoğlu T. (2018). 13-14 Yaş Arası Adölesanlarda El Boyutları İle El Kavrama Kuvvetinin Illişkisi. Sportif Bakış: Spor ve Eğitim Bilimleri Dergisi, 5(1), 9-19.

İmamoğlu A, Eliöz M, Çebi M. (2017). Kadın Futbolcularda 8 Haftalık Hazırlık Çalışmalarının Bazı Biyo-Motor Ve Fizyolojik Özellikler Üzerine Etkisi. Spor ve Performans Araştırmaları Dergisi, 8(3), 222-231.

İnce I. (2019). Effects of Split Style Olympic Weightlifting Training on Leg Stiffness Vertical Jump Change of Direction and Sprint in Collegiate Volleyball Players. Universal Journal of Educational Research, 7(1), 24-31.

Karagöz Ş, ışık Ö, Yııdııı İ. (2017). İki Farklı Hentbol Antrenmanının 11-13 Yaş Çocukların Sürat Çeviklik ve Reaksiyon Zamanı Üzerine Etkisi. Türkiye Spor Bilimleri Dergisi, 1(1), 11-20. 
Karakulak İ, Eyuboğlu E, Aslan CS. (2019). Futbolda Merkez ve Kenar Oyuncularının Fiziksel ve Motorik Özelliklerinin Karşılaştırılması. Spormetre Beden Eğitimi ve Spor Bilimleri Dergisi, 17(2), 126-131.

Kaynak K, Eryılmaz SK, Aydoğan S, Mihailov D. (2017). The Effects Of 20-M Repeated Sprint Training On Aerobic Capacity İn College Volleyball Players. Biomedical Human Kinetics, 9(1), 43-50.

Kızılet A, Atılan O, Erdemir I. (2010). The Effect Of The Different Strength Training On Quickness And Jumping Abilities Of Basketball Players Between 12 And 14 Age Group. Journal of Physical Education and Sport Sciences, 12(2), 4457.

Krističević T, Krakan I, Baić M. (2016). Effects Of Short High İmpact Plyometric Training On Jumping Performance In Female Volleyball Players. Acta Kinesiologica, 10(Suppl. 1), 25.

Küçükbaycan Ç. (2013).Orta ve Köşe Voleybol Oyuncularının Hazırlık Öncesi ve Sonrası Bacak Kuvvetlerinin Karşılaştırılması. İstanbul Üniversitesi Spor Bilimleri Dergisi, 11(3), 137-140.

Kürkçü R. (2009). Güreşçilere Uygulanan 12 Haftalık Antrenman Programının Bazı Fiziksel Ve Fizyolojik Özellikler Üzerine Etkisi. Sport Sciences, 4(4), 313-321. Martel GF, Harmer ML, Logan JM, Parker CB. (2005). Aquatic Plyometric Training İncreases Vertical Jump İn Female Volleyball Players. Medicine \& Science in Sports \& Exercise, 37(10), 1814-1819.

Mroczek D, Kawczyński A, Chmura J. (2011). Changes Of Reaction Time And Blood Lactate Concentration Of Elite Volleyball Players During A Game. Journal Of Human Kinetics, 28, 73-78.

Ölçücü B, Cenikli A, Kaldırımcı M, Bostancı, Ö. (2011). The Effects Of Movement Training With And Without Ball On Physical Fitness Of Tennis Playing Children. Spor ve Performans Araştırmaları Dergisi, 2(1), 32-40.

Pancar Z, Biçer M, Özdal M. (2018). 12-14 yaş grubu bayan hentbolculara uygulanan 8 Haftalık Pliometrik Antrenmanların Seçilmiş Bazı Kuvvet Parametrelerine Etkisi. Spor ve Performans Araştırmaları Dergisi, 9(1), 18-24.

Pérez-Turpin JA, Zmijewski P, Jimenez-Olmedo JM, Jové-Tossi MA, MartínezCarbonell A, Suárez-Llorca C, Andreu-Cabrera E. (2014). Effects Of Whole Body Vibration On Strength And Jumping Performance İn Volleyball And Beach Volleyball Players. Biology of sport, 31(3), 239. 
Popelka J, Pavlović R. (2015). The Development Of The Explosıve Leg Strength Of The Female Volleyball Team Durıng The Competition Season. Sport Scientific \& Practical Aspects, 12(2).

Ryan ED, Everett KL, Smith DB, Pollner C, Thompso, BJ, Sobolewski EJ, Fiddler RE. (2014). Acute Effects Of Different Volumes Of Dynamic Stretching On Vertical Jump Performance, Flexibility And Muscular Endurance. Clinical physiology and functional imaging, 34(6), 485-492.

Sarikaya M, Cinar V, Selçuk M, Akbulut T. (2016). Examination On The Effect Of The Training Program Implemented During Preparation Period On The Physical Characteristics Of Tennis Players. International Journal of Sport Studies, 6(10), 607-611.

Trajković N, Bogataj Š. (2020). Effects of Neuromuscular Training on Motor Competence and Physical Performance in Young Female Volleyball Players. International Journal of Environmental Research and Public Health, 17(5), 1755.

Turki-Belkhiria L, Chaouachi A, Turki O, Chtourou H, Chtara M, Chamari K, Behm DG. (2014). Eight Weeks Of Dynamic Stretching During Warm-Ups Improves Jump Power But Not Repeated Or Single Sprint Performance. European journal of sport science, 14(1), 19-27.

Voelzke M, Stutzig N, Thorhauer HA, Granacher U. (2012). Promoting Lower Extremity Strength In Elite Volleyball Players: Effects Of Two Combined Training Methods. Journal of Science and Medicine in Sport, 15(5), 457-462.

Yurkevicius BR, Bradbury KE, Nixon AC, Mitchell KM, Luippold AJ, Mayer TA., Charkoudian N. (2020). Influence of Acetazolamide on Hand Strength and Manual Dexterity During a 30-h Simulated High Altitude Exposure. Military Medicine. 